\title{
LETTERS
}

\section{Lack of COVID-19 transmission on an international flight}

In response to the CMAJ news article, "Communication, transparency key as Canada faces new coronavirus threat," ${ }^{1}$ we would like to share the public health response to the first Canadian cases of coronavirus disease 2019 (COVID-19). Case details have been published. ${ }^{2}$ The patients travelled from Wuhan to Guangzhou, then Guangzhou to Toronto, Canada, arriving on Jan. 22, 2020. The index patient was symptomatic with dry cough during the flight. His wife developed cough on Jan. 23. Both sets of throat and nasopharyngeal swabs collected were positive for COVID-19.

There were approximately 350 passengers on board the airplane. The public was notified through the media that the index case was symptomatic during the 15-hour flight. Close contacts included 25 individuals sitting within $2 \mathrm{~m}$ of the index case during the flight, flight crew members, and 1 close contact on arrival in Toronto. Close contacts received active daily contact monitoring by local public health officials for 14 days from the flight's arrival in Toronto. Passengers and crew members who were not from Ontario were referred to their home jurisdictions for follow-up. On Jan. 29, 1 close contact developed symptoms of cough; however, nasopharyngeal and throat swabs were negative for COVID-19. Non-close-contact passengers were advised to self-monitor and contact public health if they became symptomatic; 5 of these passengers became symptomatic, were tested and found by nasopharyngeal and throat swabs to be negative for COVID-19.

The United States Centers for Disease Control and Prevention recommend contact tracing 2 rows in front and behind symptomatic cases with respiratory infections owing to an elevated risk within close contact. ${ }^{3}$ However, for both severe acute respiratory syndrome-associated coronavirus (SARS-CoV) and influenza, approximately $50 \%$ of airplane transmission occurred beyond these rows. ${ }^{4}$

Studies of airplane transmission are commonly biased by contacts sharing exposure risks before boarding the aircraft. ${ }^{5}$ In our investigation, transmission may have been mitigated by mild symptoms and masking during the flight. However, the lack of secondary cases after prolonged air travel exposure supports droplet transmission, not airborne, as the likely route of spread of the COVID-19.

\section{Kevin L. Schwartz MD MSc}

Infectious disease physician, Public

Health Ontario, Toronto, Ont.

\section{Michelle Murti MD MPH}

Public health physician, Public Health Ontario, Toronto, Ont.

\section{Michael Finkelstein MD MHSc}

Associate medical officer of health, Toronto Public Health, Toronto, Ont.

\section{Jerome A. Leis MD MSc}

Infectious disease physician, Sunnybrook Hospital, Toronto, Ont.

\section{Alanna Fitzgerald-Husek MD MPH}

Associate medical officer of health, York Region Public Health, Newmarket, Ont.

\section{Laura Bourns MD}

Associate medical officer of health, Region of Peel Public Health, Mississauga, Ont.

\section{Hamidah Meghani MD}

Medical officer of health, Halton Region

Health Department, Oakville, Ont.

\section{Andrea Saunders RN MSc DTN}

Communicable diseases specialist, Public Health Ontario, Toronto, Ont.

\section{Vanessa Allen MD MPH}

Chief, Medical Microbiology, Public Health Ontario, Toronto, Ont.

\section{Barbara Yaffe MD MHSc}

Associate chief medical officer of health, Ontario Ministry of Health, Toronto, Ont.

- Cite as: CMAJ 2020 April 14;192:E410. doi: $10.1503 / \mathrm{cmaj} .75015$

\section{References}

1. Glauser W. Communication, transparency key as Canada faces new coronavirus threat. CMAJ 2020;192:E171-2.

2. Silverstein WK, Stroud L, Cleghorn GE, et al. First imported case of 2019 novel coronavirus to Canada presenting as mild pneumonia. Lancet 2020 Feb. 13 [Epub ahead of print]. doi: 10.1016/ S0140-6736(20)30370-6.

3. Protecting travelers' health from airport to community: investigating contagious diseases on flights. Atlanta: Centers for Disease Control and Prevention; reviewed 2019 Apr. 3. Available: www.cdc.gov/quarantine/contact-investigation. html (accessed 2020 Feb. 6).

4. Hertzberg VS, Weiss H. On the 2-row rule for infectious disease transmission on aircraft. Ann Glob Health 2016;82:819-23.

5. Leitmeyer K, Adlhoch C. Review article: Influenza transmission on aircraft - a systematic literature review. Epidemiology 2016;27:743-51.

Competing interests: None declared. 